\title{
Review of Switched Reluctance Motor Control for Acoustic Noise and Vibration Reduction
}

\author{
Jihad Furqani $^{*}$, Agus Purwadi ${ }^{2}$ \\ ${ }^{1}$ Department of Electrical and Electronic Engineering, Tokyo Institute of Technology, Japan \\ ${ }^{2}$ National Center for Sustainable Transportation Technology, Indonesia \\ *Email: j.furqani@yahoo.com
}

\begin{abstract}
Switched Reluctance Motor (SRM) is one of the candidates for substituting permanent magnet motor in Hybrid Electric Vehicle (HEV) application. Compared to permanent magnet motor, SRM is relatively low cost, robust, high reliability, and possible for high-temperature operation because of the absence of permanent magnet. One significant problem in SRM is the high acoustic noise and vibration. The vibration in SRM is caused by the radial forces acting at the stator teeth. Because of the saliency pole configuration in SRM, vibration is prominent. Many studies tried to reduce acoustic noise and vibration in SRM. In this paper, several controls for acoustic noise and vibration reduction are shown. The acoustic noise and vibration reduction from the experiment are also compared in each method.
\end{abstract}

\section{Keywords}

Switched reluctance motor; Radial force; Acoustic noise and vibration reduction; Voltage and current control

\section{Introduction}

Hybrid Electric Vehicle (HEV) and Electric Vehicle $(\mathrm{EV})$ are one of the solutions from the transportation sector to reduce carbon dioxide emission to the atmosphere. HEV combines conventional combustion engines with an electric motor to reduce fuel consumption while EV includes only an electric motor without the combustion engine. The electric motor employed in HEV and EV mostly is a permanent magnet motor. Permanent magnet motors have several advantages, such as high power density, high torque density, high efficiency, as well as low acoustic noise and vibration. However, in 2011 there was a sudden fluctuation cost of permanent magnet material [1]. The permanent magnet is extracted from Neodymium and Dysprosium. Neodymium and Dysprosium are called rare-earth material because almost $90 \%$ of Neodymium and Dysprosium are distributed only in China. Therefore, fluctuation cost of permanent magnet material is the problem that cannot be overlooked. Nowadays, alternative motor without a permanent magnet is one of the interesting topics among the researchers. One of the promising rareearth-free motors is Switched Reluctance Motor (SRM) [2-6].

SRM is usually called double-salient machine because both stator and rotor have a salient pole. Unlike other electric motor types, SRM only consists of iron core and winding which is the advantage in the doping maintenance. Moreover, the motor has robust stator and rotor, high-temperature operation durability, and low manufacturing cost because of the absence of permanent magnet. Power and torque density, as well as efficiency still become the problems in SRM. However, the competitive performance of SRM was found compared with the permanent magnet motor in leading HEV [7]. Another problem in SRM is highacoustic noise and vibration.

Many studies have been conducted for acoustic noise and vibration reduction. There are two main categories for acoustic noise and vibration reduction: structure improvement and voltage/current control strategies. From structure improvement, one of the examples is holes in the rotor. By making a hole in the rotor, the radial force, which causes vibration, is minimized. This paper focuses on the control strategies for acoustic noise and vibration reduction in SRM. Several control strategies are introduced, such as active vibration cancellation (AVC), direct instantaneous force control (DIFC), and current profiling.

\section{Principle of SRM}

In this section, the principle of SRM is presented to understand the origin of acoustic noise and vibration in SRM. SRM is quite similar to the step motor, except it has a fewer pole and higher output power. The pole combination depends on the number of phases. The most common SRM is three-phase SRM with least pole combination is six poles stator, and four poles 
rotor called the 6/4 SRM. Figure 1 shows the crosssection of the 6/4 SRM.

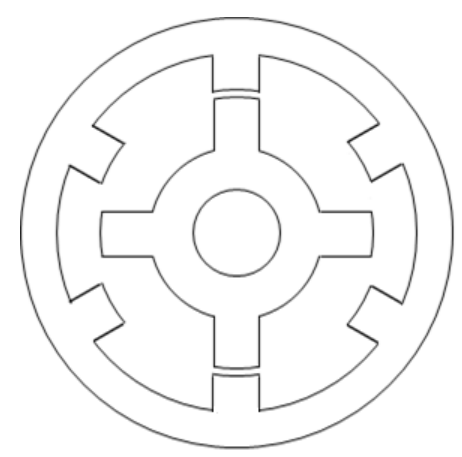

Figure 1 Cross section of the 6/4 switched reluctance motor

Rotor movement in SRM is caused by the reluctance variation. The principle of current excitation in SRM is when the rotor pole starts to align with the stator pole, the current is provided in the corresponding phase until the rotor pole moves away from the stator pole. Finally, the current in the next stages is provided. This principle is repeated for one electrical period.

Figure 2 shows the plot between flux linkage and current with the different rotational position. From Figure 2, it can be seen that SRM is easily getting saturated so that the effect of saturation cannot be neglected. In Figure 2, the saturated condition is observed for the current above $i_{s}$.

Figure 3 shows the relationship between inductance and rotational position. In Figure 3, generating and motoring region are also shown. When switched reluctance machine is operated as a motor, then phase current has to be provided in motoring region. On the other hand, phase current has to be provided in generating region when SRM is operated as a generator.

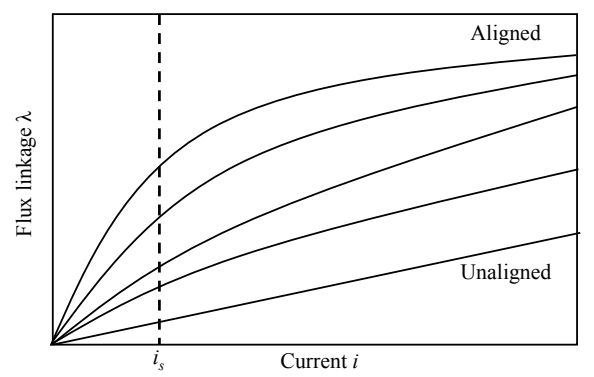

Figure 2 Flux linkage vs. current

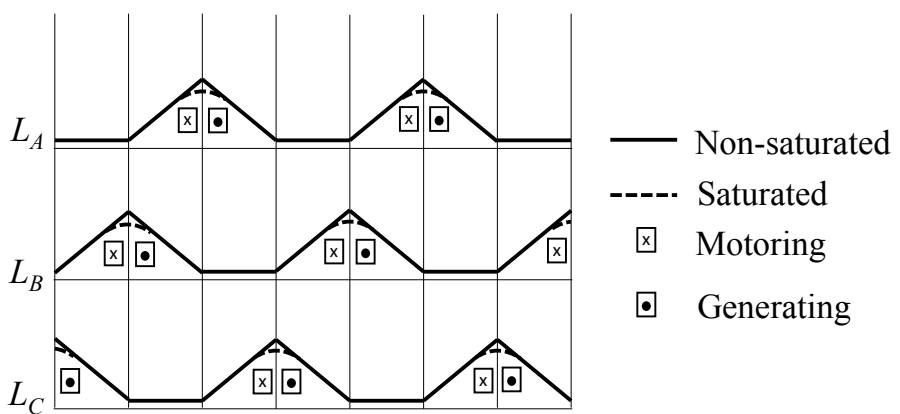

Figure 3 Inductance vs. rotational position

\section{Control for Acoustic Noise and Vibration Reduction}

There are three voltage/current control strategies to reduce the acoustic noise and vibration in SRM, namely: Active Vibration Cancellation (AVC), Direct Instantaneous Force Control (DIFC), and current profiling.

\subsection{Active Vibration Cancellation (AVC)}

AVC is introduced to reduce the vibration in SRM [8, 9]. In the AVC method, two stages of commutation are applied. Figures 4 show the principle of the AVC method. Figure 4 (a) shows the phase current and voltage waveforms. Figure 4 (b) shows the radial force and vibration waveforms.

At the $\theta_{\text {on }}$, the rotor pole starts to align with stator pole and inverter switches are turned on. $V_{d c}$ is provided to the load motor, and the current flow in the phase winding. When to rotor poles moves away from the stator pole, instead of $-V_{d c}$ voltage, zero voltage is provided for a half switching period then $-V_{d c}$ is provided to the load motor. This is the main difference between AVC and conventional method.

In the conventional method, when the rotor moves away from the stator pole, $-V_{d c}$ is directly provided to the load motor, and zero voltage is skipped. When the zero voltage is provided in the AVC method, the radial force is almost constant as shown in Figure 4 (b). The observed vibration is indicated as $a_{1}+a_{2}$ as the interaction between vibration caused by the conventional method $a_{1}$ and zero voltage $a_{2}$. Vibration $a_{1}$ and $a_{2}$ are canceling each other left fluctuation only in the half of switching period. From Figure 4 (b), it can be seen that after half switching period, vibration is significantly reduced. 


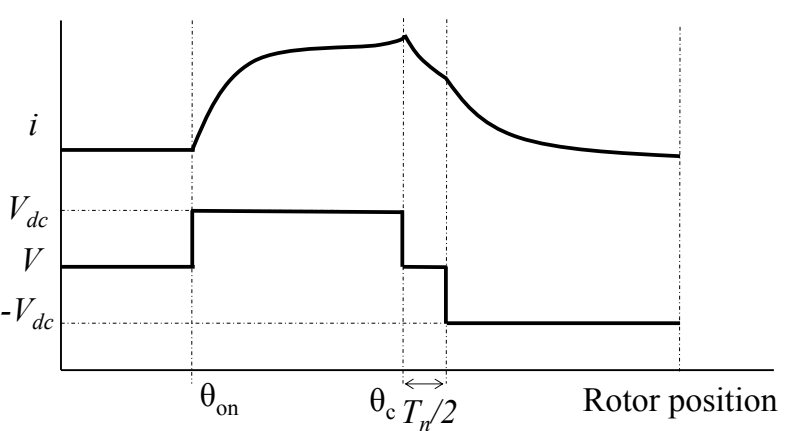

a)

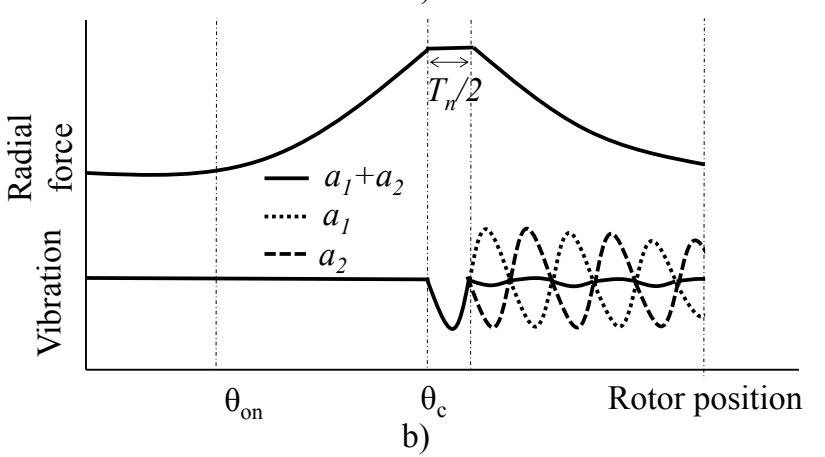

Figure 4 The principle of AVC method (a) Current and voltage waveforms; (b) Radial force and vibration

\subsection{Direct Instantaneous Force Control (DIFC)}

Vibration in SRM is caused by the radial force. In DIFC, the radial force is controlled so that the vibration can be reduced [10]. DIFC is introduced to reduce vibration in zero mode (Mode- 0 ). Mode- 0 is the expanding-shrinking deformation of the stator core as illustrated in Figure 5. High pole number SRMs usually have significant mode- 0 . Flattening radial force sum method is adapted in DIFC to reduce mode0 .

The DIFC consists of the following steps: prediction of flux linkage in the linear region, prediction of the radial force, control of the current turn-on state, adjustment of the maximum current value, and control of the current duty cycle. The generated current then flattens the sum of the radial force. Therefore, the vibration in mode- 0 is reduced.

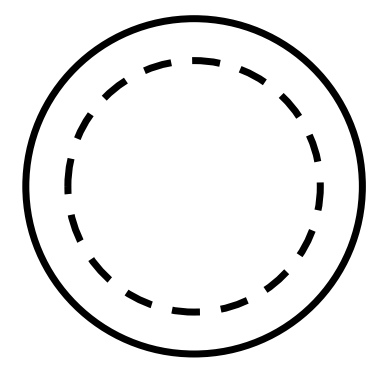

Figure 5 Mode-0 in switched reluctance motor

\subsection{Current profiling}

Acoustic noise reduction in SRM by current profiling is introduced in [11]. The principle of acoustic noise reduction is quite similar to the DIFC method. Acoustic noise reduction is attained by flattening radial force sum. The main difference is in the profile of the current. In DIFC, the square current which is the conventional current in SRM is provided. DIFC method only adjusts the duty cycle, turn-on state, and maximum value from the conventional current to acquire the flattened sum of the radial force. In the current profiling method, the sinusoidal current is introduced to flatten the sum of radial force. Moreover, current profiling method also considers a saturation state of the iron core because SRMs are usually operated in a magnetically saturated condition.

The first step of the current profiling method is the approximation of radial force in a magnetically linear and saturated condition. Then, all of the combinations of sinusoidal current are calculated. Finally, the current waveforms are selected. These steps yield to the minimum variation of the radial force sum.

Figure 6 shows a comparison between the novel and square currents. Novel current is sinusoidal current consists of dc, fundamental, second, and third harmonic components.

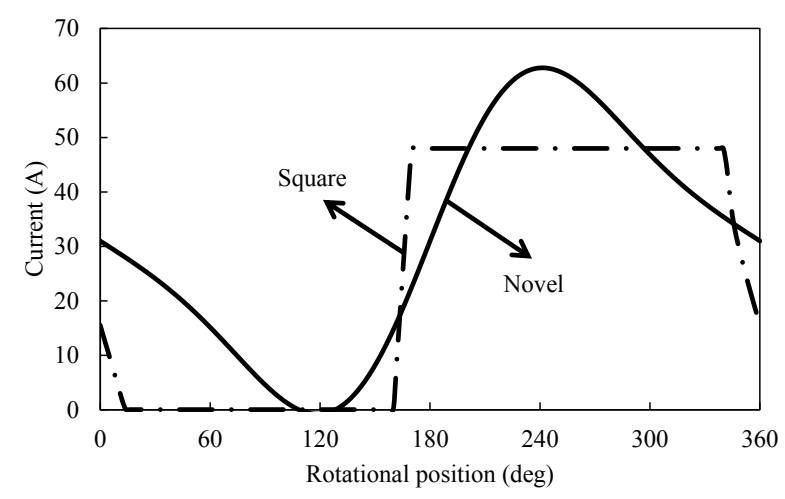

Figure 6 Comparison of novel and square currents

\section{$4 \quad$ Experiment Results}

\subsection{Active Vibration Cancellation (AVC)}

In [9], the AVC method is conducted in the 12/8 SRM which was rotating at $1500 \mathrm{r} / \mathrm{min}$. The acoustic was measured in the experiment. The natural frequency of SRM was observed at $6.8 \mathrm{kHz}$, and significant acoustic noise reduction is expected by implementing the AVC method. It results in a reduction of the acoustic noise by up to $13 \mathrm{~dB}$, but only at the natural frequency. Moreover, when the outer diameter is increased, the natural frequency is decreased and getting close to the 
fundamental harmonic. Thus, the AVC method only possible to be implemented in small outer diameter SRM.

\subsection{Direct Instantaneous Force Control (DIFC)}

In [10], the 18/12 SRM is investigated. In the experiment results, conventional and DIFC method are compared. By properly adjusting the duty cycle, turnon state, and maximum current value, vibration caused by mode- 0 can be significantly reduced. Acoustic noise from mode- 0 was reduced up to $21 \mathrm{~dB}$ by DIFC method compared with the conventional method. From this result, it can be seen that by flattening radial force sum is effective to reduce noise in SRM. However, acoustic noise and vibration reduction in the magnetically saturated condition are necessary. This is due to the SRM condition which is usually operated in a magnetically saturated state.

\subsection{Current profiling}

In [11], current profiling to reduce acoustic noise in the $36 / 24$ SRM is investigated. SRM was rotating in magnetically saturated condition at $1500 \mathrm{r} / \mathrm{min}$. The natural frequency of the SRM was observed at 1800 $\mathrm{Hz}$. By comparing novel current with square current, acoustic noise reduction up to $22 \mathrm{~dB}$ was obtained. Acoustic noise at the other frequency was also reduced significantly. Thus, the main key to reduce acoustic noise in a magnetically saturated condition is the approximation of the radial force.

\section{Conclusion}

SRM is one of the candidates for substituting permanent magnet motor HEV application. One significant problem in SRM is high acoustic noise and vibration. Vibration in SRM is caused by the radial forces acting at the stator teeth. In this paper, several controls for acoustic noise and vibration reduction are shown, such as AVC, DIFC, and current profiling. The acoustic noise and vibration reduction from the experiment is also compared in each method. AVC, DIFC, and current profiling could achieve acoustic noise reduction up to $13 \mathrm{~dB}, 21 \mathrm{~dB}$, and $22 \mathrm{~dB}$, respectively compared with a conventional method.

\section{Acknowledgment}

This work was supported by USAID through the Sustainable Higher Education Research Alliances (SHERA) program under grant number IIE00000078ITB-1.

\section{References}

[1] M. Watts, "Heavy rare earth prices take off," 2011. [Online]. Available: https://www.indmin.com/Article/2855435/Channel/19557/ Heavy-rare-earth-prices-take-off.html. [Accessed: 01-Apr2018].

[2] A. Chiba et al., "Rare-Earth-Free AC Motors-an Alternative Approach Advances," IEMDC 2011 Keynote Lect., 2011.

[3] J. M. Miller, A. R. Gale, P. J. McCleer, F. Leonardi, and J. H. Lang, "Starter-alternator for hybrid electric vehicle: comparison of induction and variable reluctance machines and drives," in Conference Record of 1998 IEEE Industry Applications Conference. Thirty-Third IAS Annual Meeting (Cat. No.98CH36242), vol. 1, pp. 513-523.

[4] C. Umemura, "Development of Switched Reluctance Motor for EV Traction System," Mar. 2001.

[5] Zhan Qionghua, Wang Shuanghong, Ma Zhiyuan, Guo Wei, and Qiu Yihui, "Design of a $50 \mathrm{~kW}$ switched reluctance machine for HEV propulsion system," in 2003 IEEE 58th Vehicular Technology Conference. VTC 2003Fall (IEEE Cat. No.03CH37484), 2003, p. 3207-3211 Vol.5.

[6] W. Wu, "Optimisation of switched reluctance motors for hybrid electric vehicles," in International Conference on Power Electronics Machines and Drives, 2002, vol. 2002, pp. 177-182.

[7] K. Kiyota and A. Chiba, "Design of Switched Reluctance Motor Competitive to 60-kW IPMSM in Third-Generation Hybrid Electric Vehicle," IEEE Trans. Ind. Appl., vol. 48, no. 6, pp. 2303-2309, Nov. 2012.

[8] C.-Y. Wu and C. Pollock, "Analysis and Reduction of Vibration and Acoustic Noise in the Switched Reluctance Drive," IEEE Trans. Ind. Appl., vol. 31, no. 1, pp. 91-98, Jan. 1995.

[9] H. Makino, T. Kosaka, and N. Matsui, "Digital PWMControl-Based Active Vibration Cancellation for Switched Reluctance Motors," IEEE Trans. Ind. Appl., vol. 51, no. 6, pp. 4521-4530, Nov. 2015.

[10] A. Hofmann, A. Al-Dajani, M. Bosing, and R. W. De Doncker, "Direct instantaneous force control: A method to eliminate mode-0-borne noise in switched reluctance machines," in 2013 International Electric Machines \& Drives Conference, 2013, pp. 1009-1016.

[11] J. Furqani, M. Kawa, K. Kiyota, and A. Chiba, "Current Waveform for Noise Reduction of a Switched Reluctance Motor Under Magnetically Saturated Condition," IEEE Trans. Ind. Appl., vol. 54, no. 1, pp. 213-222, Jan. 2018. 